\title{
CONSIDERAÇÕES ACERCA DO RECORTE ESPACIAL DENOMINADO TRÍPLICE FRONTEIRA OU FRONTEIRA TRINACIONAL DO IGUAÇU
}

Daniela Andreia Schlogel ${ }^{1}$

RESUMO: A região entre Foz do Iguaçu, no Brasil, Ciudad del Este, no Paraguai e Puerto Iguaçu, na Argentina, é conhecida comumente como tríplice fronteira, mas também se denomina região trinacional do Iguaçu/Iguassu e fronteira trinacional.O presente artigo visa demonstrar através de pesquisa bibliográfica e análise crítica que essas terminologias estão associadas à importância geopolítica da região. Conclui-se que a terminologia tríplice fronteira foi definida exogenamente, enquanto fronteira trinacional do Iguaçu têm sido construídas localmente.

Palavras-chave: região, fronteira, trinacional.

\section{CONSIDERATIONS ABOUT THE SPACE CUTTING CALLED BORDER TRIPLICE OR BORDER TRINACIONAL OF IGUAÇU}

\begin{abstract}
The region between Foz do Iguaçu in Brazil, Ciudad del Este in Paraguay and Puerto Iguaçu in Argentina, is commonly known as the triple border, but it is also called the tri-national region of Iguaçu/Iguassu and the tri-national border. The present article aims to demonstrate through bibliographical research and critical analysis that these terminologies are associated with the geopolitical importance of the region. It is concluded that the triple border terminology was defined exogenously as the tri-national region of Iguaçu have been built locally.

Keywords: region, frontier, trinational.
\end{abstract}

\section{CONSIDERACIONES ACERCA DEL RECORTE ESPACIAL DENOMINADO TRIPLE FRONTERA O FRONTERA TRINACIONAL DEL IGUAZÚ}

RESUMEN: La región entre Foz do Iguaçu, en Brasil, Ciudad del Este, en Paraguay y Puerto Iguazú, en Argentina, es conocida comúnmente como triple frontera, pero también se denomina región trinacional del Iguazú/Iguassu y frontera trinacional. El presente artículo pretende demostrar a través de investigación bibliográfica y análisis critico que esas terminologías están asociadas a la importancia geopolítica de la región. Se concluye que la terminología triple frontera fue definida exógicamente, mientras que la frontera trinacional del Iguazú ha sido construida localmente.

Palabras clave: región, frontera, trinacional.

\section{Introdução}

A região entre Foz do Iguaçu, no Brasil, Ciudad del Este, no Paraguai e Puerto Iguaçu, na Argentina, é conhecida comumente como tríplice fronteira, mas também se denomina região trinacional do Iguaçu/Iguassu e fronteira trinacional. Este artigo procura explicar a diferença destas nomenclaturas e fazer considerações sobre o recorte espacial em questão. A base metodológica utilizada foi pesquisa bibliográfica e análise crítica de dados. Primeiramente são apresentados os conceitos de fronteira e de região, posteriormente são apresentados aspectos gerais da região em questão e em seguida é levantada a importância geopolítica deste local.

\section{Fronteira}

\footnotetext{
${ }^{1}$ Doutoranda em Desenvolvimento Econômico na UNICAMP. Mestre em Integração Contemporânea da América Latina pela UNILA e bacharel em Ciências Econômicas, Integração e Desenvolvimento pela UNILA. E-mail: danielaschlogel@gmail.com
} 
A noção de fronteira pode assumir diferentes conotações. No âmbito da conotação política, são consideradas fronteiras dos países o limite da sua base territorial terrestre, e também dos espaços aéreos e marítimos sob sua jurisdição (SELA, 2012).

No plano da análise social, em que se pretende apreender o movimento das relações e da construção social, as fronteiras estão em toda parte, e vão das mais concretas às mais abstratas. As fronteiras podem ser limites estabelecidos entre diferentes culturas ou grupos socais. A fronteira entre brasileiros e os seus vizinhos pode ser representada pela língua diferente, ou pela diferença cultural entre um descendente de europeu e um descendente dos povos originários.

Em um âmbito ainda mais específico, o da constituição da nossa identidade pessoal, estabelecemos limites e fronteiras para definir quem somos. É sabendo e reconhecendo o outro como o que não somos nós, como o que está além da fronteira entre o ser ou não ser eu, que tentamos definir quem somos. Isto significa que as fronteiras são importantes elementos constitutivos da vida das pessoas em diversos níveis de análise.

As fronteiras políticas dos países, definidas em latitudes e longitudes, são limites concretos. Porém as relações que se estabelecem nestes espaços estão constantemente reforçando-as ou transcendendo-as.

Segundo Albuquerque (2009), “as fronteiras nacionais são fenômenos complexos, não se resumem a limites, divisas, tratados diplomáticos, nem podem ser simplificados como o lugar do narcotráfico e do contrabando". Para além disso, as fronteiras "são criações humanas, delimitadas e demarcadas sucessivamente de acordo com os processos e ocupação militar, demográfica, econômica, política e cultural que ocorrem nos territórios limítrofes" (ALBUQUERQUE, 2009, p. 159).

As fronteiras podem ser interpretadas de inúmeras formas e assumem inúmeros significados para as pessoas que vivem nestes locais e se relacionam diferentemente com eles. Por exemplo, para um trabalhador brasileiro que mora no Brasil e trabalha no Paraguai há muitos anos, a fronteira é apenas seu caminho para o trabalho. Para um contrabandista, é um local de vigília; para uma criança que acompanha os pais na compra do presente de natal repetidas vezes, é um local de memória afetiva. Para um governante, é local de relações diplomáticas; para um comerciante, é onde se pode explorar as diferenças cambiais.

Em inglês existem dois termos usados para identificar fronteira, cada um significando-a de uma forma específica. Segundo Albuquerque,

As palavras inglesas border e frontier permitem diferenciar dois sentidos do termo fronteira: border seria a fronteira como divisão política e administrativa, já frontier é a ideia de expansão, de conquista, de movimento constante. A fronteira passa a ser entendida como uma zona de transição entre um espaço geográfico ocupado de maneira estável e contínua por uma sociedade nacional e 
um outro que, desde a perspectiva dominante desta sociedade, se encontra livre, embora já esteja ocupado por povos indígenas, camponeses, posseiros, etc (ALBUQUERQUE, 2009, p.160).

Estas duas concepções, uma apresentando a fronteira como um limite bem estabelecido e a outra como uma barreira que, assim que possível, poderá ser ultrapassada ou conquistada, são as principais definições de fronteira encontradas na bibliografia sobre o tema.

Para os moradores dos países que vivem na região da fronteira, ela pode ainda adquirir outros significados pessoais que vão variar do acordo a função que ela representa dentro da reprodução da vida material e simbólica destes moradores.

O estudo do SELA (2012) intitulado "La integración fronteriza en el marco del proceso de Convergencia de América Latina y El Caribe" diferencia duas noções que fazem parte da ideia de fronteira: a de "lianealidad" e a de "zonalidad", que poderiam ser traduzidas como linearidade e zonalidade.

A linearidade tem a ver com o conhecimento preciso dos limites do território. Tem conotação jurídica e consta em tratados internacionais.

A zonalidade tem conotação econômica e social,

En el sentido de constituir la manifestación, en una porción de territorio situado en los confines de un Estado, de fuerzas organizadas que actúan de un lado al outro del limite y cujos vectores son la población y los acondicionamientos de todo tipo (SELA, 2012, p. 9).

Pode-se considerar a linearidade e a zonalidade como duas dimensões da fronteira trinacional.

No Brasil, no âmbito da linearidade, as normas referentes à fronteira são estabelecidas pela Lei 6.634 de 2 de maio de 1979 e pelo decreto 85.064 de 26 de agosto de 1980. Ambas do período da ditadura militar. Nelas são definidas que a faixa de fronteira compreende $150 \mathrm{~km}$ de largura paralela à linha divisória do território (BRASIL, 1979), e que esta faixa é considerada área indispensável de segurança nacional (BRASIL, 1980). Foz do Iguaçu está compreendida nesta área, e isso impede que os estrangeiros possuam empresas em determinados ramos sem autorização do Conselho de Defesa Nacional. Esta área, ou zona, é receptora de políticas públicas específicas para áreas de fronteira nos três países. Estas iniciativas existem de forma isolada e coordenada e também podem ser provocadas pela iniciativa privada.

O âmbito da zonalidade se refere às relações econômicas, sociais e culturais estabelecidas entre as cidades estudadas. É neste âmbito que estão as atividades produtivas que ao movimentarem economicamente um lado da fronteira acabam provocando uma dinâmica que ecoa para além das linhas divisórias. 
Em 2005 houve uma iniciativa por parte do governo brasileiro para coordenar as ações e programas no que tange às fronteiras brasileiras. Para tanto foi elaborado o documento intitulado 'Proposta de Reestruturação do Programa de Desenvolvimento da Faixa de Fronteira', elaborado em colaboração entre o Ministério da Integração Nacional e a Universidade Federal do Rio de Janeiro (UFRJ). O documento utiliza a noção de fronteira como 'zona', semelhante a ideia de zonalidade apresentada pelo SELA (2012).

Segundo esta proposta de reestruturação, para um estudo regional que corresponda à realidade de um local, a concepção da fronteira como limite deve ser diferenciada da noção de fronteira como uma zona. A zona de fronteira é um foco mais apropriado para a análise de uma região fronteiriça, porque considera o espaço de interação que se estabelece ao redor dos limites oficiais.

Ao deslocar o enfoque de uma concepção 'linear', própria à noção de limite ou divisória internacional, para uma concepção de área ou região de fronteira, introduziu-se uma distinção muito relevante para este trabalho, entre faixa e zona de fronteira. Enquanto a faixa de fronteira constitui uma expressão de jure, associada aos limites territoriais do poder do Estado, o conceito de zona de fronteira aponta para um espaço de interação, uma paisagem específica, com espaço social transitivo, composto por diferenças oriundas da presença do limite internacional, e por fluxos e interações transfronteiriças (BRASIL, 2005, p.21).

As zonas de fronteira correspondem a esta área de interação transfronteiriça que ocorre perto da linha divisória entre os países e principalmente através dela.

As cidades em zona de fronteira que são caracterizadas por "adensamentos populacionais" divididos pela fronteira, e que apresentam considerável "potencial de integração econômica e cultural", além de compartilharem problemas comuns, são chamadas de cidades gêmeas. Estas possuem sede próxima à linha divisória (BRASIL, 2005, p. 152). Foz do Iguaçu é considerada a maior cidade gêmea do Brasil pelo fluxo intenso de relações registrado com Ciudad del Este.

\section{Região ${ }^{2}$}

Concebe-se o recorte espacial citado como região porque observa-se na realidade concreta que as articulações entre as três cidades e seu entorno fazem com que elas pertençam a um espaço maior do que aquele determinado pelas suas fronteiras. Um território com características peculiares que o distingue de outros e lhe confere certa unidade.

\footnotetext{
${ }^{2} \mathrm{O}$ uso do conceito de região aqui, distingue-se daquele usado pelos autores que trataram da 'Questão Regional'. Para Francisco de Oliveira (1993), a 'Questão Regional' se refere à fratura da unidade nacional representada pelas disparidades, como por exemplo, entre o Nordeste e o Sudeste. O conceito de região surgiu na geografia em meados do século XIX, definida como um espaço com características físicas semelhantes. No decorrer do desenvolvimento científico este conceito passou por um amplo processo de metamorfose (BRITO, 2007).
} 
Esta definição baseia-se nas ideias de Santos (2006, p.90) que coloca o termo 'região' como um 'vocábulo geográfico' que, assim como o 'lugar', possui ambiguidades e serve para 'designar extensões diferentes'.

A região pode ser entendida como uma delimitação proposital, que destaca as relações estabelecidas entre os lugares que os aproximam e os diferenciam de outros, concedendo a estes certa coesão que permite agrupá-los em uma região.

Para Santos,

Num estudo regional se deve tentar detalhar sua composição enquanto organização social, política, econômica e cultural, abordando-lhe os fatos concretos, pra reconhecer como a área se insere na ordem econômica internacional, levando em conta o preexistente e o novo, para captar o elenco de causas e consequências do fenômeno (SANTOS, 1988, p.17).

A definição do que é uma região é um tema amplamente abordado por correntes metodológicas distintas. Neste estudo, parte-se do pressuposto defendido por Brandão (2012) de que não é possível que uma teoria abstrata defina uma categoria em que caibam todas as regiões existentes. Por isso realizamos este recorte específico sob o qual se desenvolve esta pesquisa.

\section{Tríplice Fronteira ou Região Trinacional do Iguaçu?}

A Região Trinacional do Iguaçu é um dos pontos de encontro entre Brasil, Paraguai e Argentina e o único em que eles se encontram simultaneamente.

Os limites do Brasil têm $23.086 \mathrm{~km}$ de extensão, sendo 7.367 de costa banhada pelo Oceano Atlântico, e uma extensão terrestre de 15.719 km (IBGE, 2016a). Abrange todos os países da América do Sul, exceto Equador e Chile.

A Argentina faz fronteira com o Uruguai, o Brasil, o Paraguai, a Bolívia e o Chile. Segundo o INDEC (2014), a extensão da fronteira argentina é de $25.728 \mathrm{~km}$. Parece estranho que esta extensão seja maior que a do Brasil, isso ocorre porque a Argentina possui, além dos limites terrestres e da costa atlântica, algumas ilhas e uma parte de território antártico. As fronteiras com os países vizinhos são de $9.376 \mathrm{~km}$.

A fronteira entre o Brasil e a Argentina tem 1.261 km, que vai de Puerto Iguazú a Paso de los Libres.

O Paraguai não possui saída ao mar, é um país mediterrâneo. Seus limites totalmente terrestres fazem fronteira como Brasil, a Argentina e a Bolívia. A fronteira do Brasil com o Paraguai tem 1.365 km de extensão. Ela começa entre Foz do Iguaçu e Presidente Franco e vai até Alto Paraguai. Termina com outra fronteira tripla entre Brasil, Paraguai e Bolívia. A faixa de fronteira perpassa rios, matas, áreas inabitadas e rodovias. 
A área de fronteira trinacional localizada entre Foz do Iguaçu, Ciudad del Este, Puerto Iguazú e seu entorno recebe grande fluxo de pessoas e é considerada uma região peculiar, que soma-se ao fato de ter atrativos naturais, comerciais e geoestratégicos.

Este local possui representativa heterogeneidade étnica e cultural, além da convivência das culturas dos três países, recebe "imigrantes internacionais de origens menos comuns" como coreanos, chineses e árabes, atraídos pelas oportunidades de desenvolver atividades comerciais (IPARDES, 2008, p.62).

A região é conhecida comumente pela nomenclatura "tríplice fronteira" e foi evidenciada no pós anos 1990 como uma área de segurança a ser observada permanentemente.

Segundo o IPARDES (2008), a cidade era conhecida como a região das três fronteiras, e essa concepção foi substituída pela ideia de "tríplice fronteira" construída exogenamente. A construção da ideia de tríplice fronteira foi constituída "associada à suspeita da presença de terroristas islâmicos na região". Divulgada na mídia nacional e internacional como um espaço transnacional que está para além do controle estatal e em constante ameaça do "terrorismo global” (RABOSSI, 2004; BÉLIVEAU, 2006 apud IPARDES, 2008, p. 62).

Para Amaral (2010), a nomenclatura 'Triborder Area', traduzida como "tríplice fronteira" começou a ser usada em documentos norte-americanos quando o local virou uma preocupação daquele país. Após os atentados ocorridos em Buenos Aires em 1992 e 1994 contra a uma embaixada e uma associação israelita, a região passa a integrar o "mapa norte-americano de potenciais espaços de atuação do terrorismo internacional" (AMARAL, 2010, p. 140).

Para conhecer as principais cidades integrantes da região trinacional do Iguaçu é necessária uma apresentação descritiva e um breve levantamento histórico sobre a constituição de cada uma delas.

Foz do Iguaçu é uma cidade brasileira de porte médio, com cerca de 260 mil habitantes ${ }^{3}$. O local recebe cerca de 1,6 milhão de turistas por ano. Desmembrada do município paranaense de Guarapuava, virou distrito em 1910 e cidade em 1914. Segundo IBGE (2016b), Foz do Iguaçu tem aproximadamente $617 \mathrm{~km} 2$, densidade demográfica de 414,58 hab/km2 e IDH de 0,751. Seus limites do lado brasileiro são as cidades de Itaipulândia, Santa Terezinha de Itaipu e São Miguel do Iguaçu. Seus limites com outros países são os rios Iguaçu e Paraná que fazem divisa com as cidades de Puerto Iguazú, Ciudad del Este e Presidente Franco.

Puerto Iguazú tem aproximadamente 80.000 habitantes e recebe anualmente cerca de 1,1 milhão de turistas para visitar principalmente as Cataratas do Iguaçu, que podem ser vistas tanto pelo lado argentino quanto pelo lado brasileiro. Ainda que seja o mesmo atrativo turístico, cada

\footnotetext{
${ }^{3}$ Foz significa o local onde o rio deságua, e Foz do Iguaçu, o local onde o rio Iguaçu encontra os outros rios. A palavra guarani Iguaçu significa "água grande".
} 
lado permite a observação de uma paisagem em particular. A pequena cidade argentina também tem como peculiaridade os Cassinos, casas de jogos que são proibidas no Brasil.

O Parque Nacional do Iguaçu, onde estão localizadas as cataratas, é ligado pelo rio Iguaçu ao Parque Nacional Iguazú, o que faz com que Brasil e Argentina coordenem ações de preservação da área. O Parque do lado brasileiro foi criado em 1939 e em 1986 foi reconhecido como Sítio do Patrimônio Mundial Natural da UNESCO. O Parque abriga o maior remanescente de floresta amazônica do Sul do Brasil. Juntos, o lado argentino e brasileiro formam o mais importante corredor de conservação biológica da região. O Parque Argentino foi criado em 1934 e considerado Patrimônio da Humanidade da UNESCO em 1984. Ambos os parques haviam sido propriedades privadas antes de serem considerados área de interesse público.

Ciudad del Este tem aproximadamente 350 mil habitantes e é a segunda cidade mais importante do Paraguai. A diferença entre a cobrança de impostos entre esta e os dois vizinhos torna a cidade paraguaia um lugar vantajoso para se comprar produtos estrangeiros; este fato também é considerado um motivo de atração de pessoas ao local. O lado paraguaio da Itaipu Binacional, assim como no lado brasileiro, é um atrativo turístico, e os dois receberam juntos cerca de 860 mil visitantes em 2015. Os números cresceram ao longo dos últimos anos. O ano de 2015 apresentou a quebra de vários recordes da região. Foi nesse ano que o aeroporto Internacional de Foz do Iguaçu apresentou o maior movimento da sua história, com 2.057.278 embarques e desembarques. E as cataratas do Iguaçu receberam o maior número de visitantes já registrados, 1.642 .093 pessoas de 172 nacionalidades (ITAIPU, 2016).

A região pode ser considerada uma grande área de uso comum, dividida ou unida pelos seus limites oficiais, não existem grandes áreas desocupadas entre as cidades. O fluxo na ponte que liga o Brasil ao Paraguai é de 10 a 20 mil pessoas por dia (CURY e FRAGA, 2013). Juntas, as três cidades formam uma área urbanizada com cerca de 700 mil habitantes.

Foz do Iguaçu têm cidades vizinhas como Santa Terezinha, São Miguel do Iguaçu e Santa Helena, que se relacionam diretamente com a cidade, já que esta é o maior centro urbano próximo destas. Já Ciudad del Este tem ao lado a cidade de Presidente Franco, que também faz fronteira com a Argentina e se relaciona intensamente com Ciudad del Este.

É sabido que o tratado que definiu as fronteiras entre o que seria território de colonização Espanhola ou Portuguesa foi o Tratado de Tordesilhas em 1494. Sob essa divisão a região trinacional em foco era território de domínio Espanhol e foi novamente definida pelo Tratado de Madri em 1750, ficando então com o desenho semelhante ao encontrado nos dias de hoje. Porém, mesmo com tal definição, o idioma que se falava em toda essa região ainda no início do século XX era o espanhol e a maioria dos moradores era descendente de paraguaios (SILVA, 2014, p. 22). 
Para José Maria de Brito, sargento da expedição militar, que participou da abertura da "picada" que veio a ligar Foz do Iguaçu ao resto do país em 1888, a ocupação desta região era estratégica para o governo brasileiro e por isso reuniram-se esforços para alocar uma colônia militar na região. Para o desbravador,

Desde o ano de 1880, ainda antes da morte do maior General brasileiro, o pacificador Duque de Caxias, entre os oficiais do Exército mais aproximados ao Ministério da Guerra, já era um dos assuntos mais discutidos a descoberta de Foz do Iguaçu, principalmente por ser um ponto estratégico, diziam alguns, bem como a fundação de uma Colônia Militar e a construção de um forte, com capacidade suficiente para opor obstáculos a nações estrangeiras que porventura tentassem invadir o nosso território (BRITO, 2005 [1938], p. 29).

Puerto Iguazú foi fundada em 1901, quando se começou a construir o caminho para as Cataratas, com o nome de Puerto Aguirre. Em 1943 foi elevada a condição de Município (CONTE, 2012). Ciudad del Este foi fundada em 1957, um ano depois do acordo assinado entre o Brasil e o Paraguai para a construção da Ponte da Amizade. A Cidade se chamou Puerto Presidente Stroessner até o fim da ditadura paraguaia. Após 1989 passou a chamar-se Ciudad del Este.

Segundo REOLON (2007 aput CONTE, 2012), o Oeste do Paraná passou por quatro fases de ocupação territorial: a primeira fase é a de ocupação indígena, assim como toda a América do Sul; a segunda foi a do período de instalação e colonização europeia através dos Jesuítas; a terceira situada no final do século XIX é caracterizada pela implantação do sistema obrageiro $^{4}$. A quarta, após os anos 1940, foi a fase das companhias colonizadoras.

As companhias colonizadoras eram empresas privadas contratadas pelo Estado para promover o que faltava da ocupação do espaço com o propósito de integrá-lo ao território nacional. Estas empresas realizaram a organização fundiária, dividindo a terra em pequenas propriedades. Os novos proprietários eram fundamentalmente originários do Sul do Brasil, descendentes de alemães e italianos e alguns mineiros e paulistas (CONTE, 2012).

Percebe-se que a herança hispano-americana ainda se fazia bastante presente no início do século XX, porque do lado brasileiro, foi decretado em 1930 pelo presidente Getúlio Vargas a obrigatoriedade do uso do idioma Português e da moeda nacional nesta região (SILVA, 2014); (LIMA, 2001). Mostrando que, já definida a fronteira política, a dimensão cultural da fronteira ainda era motivo de preocupação e imposição do Estado-Nação.

\footnotetext{
${ }^{4} \mathrm{O}$ sistema de exploração de madeira e erva mate que prevaleceu na região no final do século XIX e ainda início do século XX é chamado de "obrageiro". Segundo Silva (2014, p. 26-7) "Um obrageiro era um argentino dono de uma obrage, que era uma empresa privada responsável pela extração e transporte da erva-mate e da madeira". O governo do Estado do Paraná concedia autorização para tal atividade.
} 
Nas décadas de 1960 e 1970 houve mudanças que transformaram definitivamente o território trinacional. Em primeiro lugar, a construção da ponte internacional da Amizade em 1965 que aproximou intensamente Brasil e Paraguai. E posteriormente a construção da Usina Hidrelétrica Itaipu Binacional. Foi neste período também que as populações das cidades da região sofreram incremento significativo. Ciudad del Este contava com uma população de 26.485 habitantes em 1972 e passou para 62.328 em 1982. Puerto Iguazú contava com 3.001 em 1970 e passou a ter 10.250 habitantes em 1980 (IPARDES, 2008, p. 61). Foz do Iguaçu que possuía 33.966 habitantes em 1970, passou a ter 136.321 em 1980 (IPARDES, 2008, p.16). Após esse "boom" demográfico, as três cidades seguiram ritmo acelerado de crescimento populacional.

A partir destes dados reforça-se a ideia de que existe uma influência mútua entre o desenvolvimento econômico e social destes três municípios que compõe a Região Trinacional do Iguaçu. $\mathrm{O}$ crescimento populacional articulado mostra que não se explica nenhuma das três cidades sem falar das outras.

\section{Localização Estratégica}

A denominação de uma região é a forma como ela é reconhecida pelos seus moradores e por atores externos. O fato de uma região chamada de tríplice fronteira passar a ser chamada de região trinacional do Iguaçu/Iguassu é sutil, porém não acontece ao acaso. A definição de uma denominação de região ser definida exogenamente, ou por sujeitos que fazem parte da construção social do referido espaço, é uma disputa simbólica associada ao fato da região ser um local estratégico geopoliticamente.

Pensando na região trinacional como espaço de importância geopolítica, é possível fazer o exercício de puxar a linha já desenhada por estrategistas que discutiram a definição de um possível heartland sul-americano até este local. Embora o conceito tenha surgido na Europa e em outros tempos, autores como Travassos ([1938] apud HAGE, 2013), Severo (2012), Hage (2013), Albuquerque (2013) e Rodrigues (2014) já trabalharam a importância de se dominar uma região terrestre intracontinental estratégica, para a dominação de todo continente sul-americano.

O heartland seria uma área considerada o coração do continente, que possibilitaria o acesso a diferentes localidades pela parte interna. Estes autores falaram do território compreendido entre a Bolívia e o Mato Grosso do Sul. Pesquisando a região trinacional podemos encontrar razões que a incluem nesta área.

O autor Hage (2013), comentando obra de Travassos, já cita Foz do Iguaçu como exemplo de preocupações geoestratégicas no começo do século passado: 
O debate enaltecido por Travassos era para que o poder brasileiro em voga, governo Getúlio Vargas, compreendesse a urgência de se instituir projeto político que tivesse duas preocupações. Primeira que houvesse esforços para se integrar o território brasileiro da melhor forma possível, aproveitando seus recursos hídricos e econômicos, sobretudo em territórios considerados vulneráveis a atração portenha, como Foz do Iguaçu (HAGE, 2013, p.3).

$\mathrm{Na}$ época citada, a presença argentina na região se dava fortemente pelas "obrages", empresas argentinas que tinham concessão de terras, fornecida pelo Brasil, para exploração de erva mate e madeira, em troca de fazer benfeitorias na região. Esse sistema de exploração durou até as primeiras décadas do século XX. Nesse período, toda a região era chamada simplesmente de Iguaçu ou Iguazú. Após a instalação da colônia militar e o fim das obrages, eram os militares que decidiam quem ganharia terra e quem poderia plantar (SILVA, 2014).

Após o ciclo econômico de exploração da madeira e da erva mate, a principal atividade econômica da região foi a agricultura. Essas atividades fazem parte do padrão de reprodução do capital agromineiro exportador ${ }^{5}$ observado em grande parte da América Latina naquele período (OSÓRIO, 2012).

Quando o heartland começou a ser discutido no meio político e acadêmico na década de 1930, a preocupação era a ascensão norte-americana através da dominação da América do Sul, além de um certo receio da ascensão argentina. Após a criação do Mercosul e a aproximação do Brasil e da Argentina, esta rivalidade deu espaço para uma certa cumplicidade. Com a entrada da Bolívia no Mercosul, o heartland está sob a influência do bloco. Para a proteção dessa área, é necessário que as relações intramercosul sejam democráticas e que o bloco seja igualmente vantajoso para os países grandes e pequenos

É preciso usar esses conceitos da geopolítica, articulados com a teoria social crítica. Pois, a construção social do território é que define se um determinado local estratégico servirá para a dominação ou para uma outra forma de produção e reprodução da organização da vida em sociedade.

Outro aspecto relevante que coloca a região como área de interesse internacional é a riqueza em recursos hídricos. Essa região é banhada pela Bacia do Prata e pelo Aquífero Guarani. O Aquífero se estende pelos quatro países do cone sul e é o "maior manancial subterrâneo transfronteiriço do mundo" (ANTUNES, 2007, p. 18).

Com o fortalecimento do Mercosul após os anos 2000, a importância estratégica desta região trinacional se evidencia. A fundação de uma universidade que estude a integração latinoamericana, como a UNILA neste local reforça este argumento.

\footnotetext{
${ }^{5}$ O padrão de reprodução do capital caracterizado como agromineiro exportador esteve presente na América Latina entre o século XIX e o início do século XX, é representado por atividades como plantação de trigo, criação de gado e enclaves mineiros (OSORIO, 2012).
} 
Foi a partir da última onda integracionista, após os anos 2000, que as exportações e importações intramercosul mais do que triplicaram e o fluxo de pessoas na região aumentou (MDIC, 2015; ITAIPU, 2016). A região passou a aparecer recorrentemente dentro dos projetos mais amplos de integração.

Um dos problemas da integração da América do Sul é a deficiência na integração física dos países. Com o objetivo de construir soluções para tal gargalo, foi criada a Iniciativa para a Integração da Infraestrutura Regional Sul-americana (IIRSA). Tal iniciativa teve origem na Reunião de Presidentes da América do Sul que aconteceu no Brasil nos anos 2000. Na ocasião, os presentes "acordaram realizar ações conjuntas para avançar na modernização da infraestrutura regional e na adoção de ações específicas para promover a integração e o desenvolvimento socioeconômico" (IIRSA, 2009, p.7).

Posteriormente a IIRSA foi integrada à Unasul ${ }^{6}$, ficando sob responsabilidade do COSIPLAN (Conselho Sul-americano de Infraestrutura e Planejamento).

O surgimento da IIRSA se deu sob as bases do regionalismo aberto. Algumas críticas realizadas à iniciativa afirmam que seus projetos visam "integrar a região ao exterior antes de integrar os países sul-americanos entre si” (COSTA, MENGER \& TANCREDI, 2015, p.12).

Apesar das críticas a região trinacional de Foz do Iguaçu, Ciudad del Este, Puerto Iguazú e seu entorno é contemplada pela carteira de projetos da IIRSA em vários eixos com projetos que beneficiam a integração regional. Os financiadores são do Banco Interamericano de Desenvolvimento (BID), o Fondo Financiero para el Desarrollo de los Países de la Cuenca del Plata (FONPLATA) e a $\mathrm{CAF}^{7}$. Um dos projetos que contempla a fronteira entre Foz do Iguaçu e Ciudad del Este é o de Facilitação da Passagens de Fronteira, considerado um dos projetos setoriais de integração "chave para a mobilidade de bens e pessoas na região" (IIRSA, 2009, p. 24). Para a IIRSA, este tipo de projeto:

Busca converter a fronteiras em canais de uma verdadeira integração, abordando o tema de forma multidimensional e atendendo aos aspectos econômicos, legais, logísticos, e informáticos que envolvam transporte rodoviário (IIRSA, 2009, p. 24).

A IIRSA é dividida em eixos de integração. Em cada eixo, existem grupos de projetos. Os projetos que tratam da região estudada estão fundamentalmente no Eixo de Capricórnio nos grupos 3 e 4. Mas também são diretamente afetados pelos projetos que se encontram no Eixo Hidrovia Paraguai - Paraná, no Eixo Interoceânico Central e no Eixo Mercosul - Chile. Outro

\footnotetext{
${ }^{6}$ Criada em 2008, a Unasul (União das Nações Sul-americanas) é um espaço de articulação e diálogo político dos 12 países da América do Sul.

${ }^{7}$ A Corporação Andina de Fomento (CAF) fundada em 1968 se expandiu na década de 1990 e recentemente passou a se autodenominar 'O Banco de Desenvolvimento da América Latina'.
} 
projeto que contempla a região é o de construção de uma ferrovia que ligará as cidades Cascavel, Foz do Iguaçu, Guaíra do Estado do Paraná à Maracaju no Estado do Mato Grosso do Sul. Este projeto está em fase de análise de uma proposta de modificação sugerida pelo Brasil.

Existe também o projeto de construção de uma segunda ponte ligando o Brasil ao Paraguai, chamada de Nova Ponte Presidente Franco - Porto Meira que já foi licitada e contratada.

Constam também projetos de melhoramento das rodovias 2 e 7 que ligam Ciudad del Este a Assunción e interferem diretamente na região. Além da construção de uma ferrovia entre estas duas cidades. É prevista também uma ponte ferroviária com pátio de cargas entre Foz do Iguaçu e Ciudad del Este. E uma linha de transmissão Yaciretá - Ayolas - Carayao na Argentina.

Os outros projetos que contemplam a região são: a construção de um centro de fronteiras em Puerto Iguazú; a construção de uma ferrovia de Ciudad del Este a Pilar; a construção de uma ponte entre Presidente Franco e Puerto Iguazú; e o melhoramento e concessão da Rodovia Nacional 6 que liga Ciudad del Este a Encarnación.

Todos estes projetos evidenciam mais uma vez a importância do local enquanto região articulada, com importância geopolítica e pensada em conjunto. Portanto, o grupo social que define a forma como ela será conhecida ou denominada também demonstra influência sobre a região. A denominação Tríplice Fronteira, relacionada a região como ameaça, e cunhada externamente, têm sido substituídas por conceitos cunhados internamente, como Região Trinacional do Iguaçu/Iguassu e Fronteira Trinacional. Este reemplazamiento demonstra a reafirmação sobre o espaço de grupos sociais que fazem parte da construção social deste. Isso acontece quando estes grupos locais denominam a região a partir de suas perspectivas

\section{Considerações Finais}

A Região Trinacional do Iguaçu foi por muitos anos conhecida como Tríplice Fronteira, conceito cunhado exogenamente e que relacionava a região a um lugar de vigilância que poderia representar ameaças de terrorismo.

Conceitos como Região da Fronteira Trinacional e Região Trinacional do Iguaçu começaram a aparecer em textos acadêmicos após o início deste século (DEBALD, 2005, SOUZA E CORREA, 2008, OLIVEIRA, 2005). Documentos do Mercosul também utilizam estes termos para se referir a região (CMC/DEC. N. ${ }^{\circ}$ 02/2009).

Uma variação desta nomenclatura aparece com uma escrita alternativa da palavra Iguaçu, escrita como Iguassu, num esforço de tornar a palavra mais fluente para as pessoas nativas em idiomas que não utilizam o "ç". As instituições que mais utilizam esta alternativa estão geralmente ligadas ao turismo, como por exemplo, o Instituto Polo Iguassu - instituição de 
direito privado, sem fins econômicos, presente na região - que utiliza esta escrita em seu nome, em seus documentos e em suas matérias de divulgação, e também o Observatório Trinacional de Turismo Iguassu - núcleo de estudos e pesquisas sobre turismo na região.

Conclui-se que os conceitos de Região Trinacional do Iguaçu/Iguassu e Fronteira Trinacional diferentemente do conceito de Tríplice Fronteira estão relacionados com uma denominação de região criada de dentro para fora, por sujeitos que participam da construção social do referido espaço e procuram se reafirmar sobre o mesmo.

\section{Referências}

ALBUQUERQUE, José Lindomar Coelho. A Dinâmica das Fronteiras: Deslocamento e circulação dos 'brasiguaios' entre os limites nacionais. Revista Horizontes Antropológicos. Porto Alegre, ano 15, n. 31, p. 137-166, jan./jun. 2009.

ALBUQUERQUE, Edu Silvestre de. A disputa pelo "Coração das terras" sul-americanas. Revista contexto e educação. Editora Unijuí. Ano 28, no. 89.p. 148-169. Jan/Abr 2013.

AMARAL, Arthur Bernardes do. A Tríplice Fronteira e a Guerra ao Terror. Rio de Janeiro: Apicuri, 2010.

ANTUNES, José Cerqueira. Infraestrutura na América do Sul: situação atual, necessidades e complementaridades possíveis com o Brasil. Brasil: CEPAL, 2007.

CMC. Conselho Mercado Comum. Decisão n02 de 2009.

BRANDÃO, Carlos Antônio. Território e Desenvolvimento: as múltiplas escalas entre o local e o global. Campinas: Editora da UNICAMP, 2012.

BRASIL. Lei n. 6.634 de 2 de maio de 1979. Dispõe sobre a Faixa de Fronteira, altera o decreto 1.135, de 3 de dezembro de 1970, e dá outras previdências. Disponível em: http://www.planalto.gov.br/ccivil_03/LEIS/L6634.htm Acesso em: $10 \mathrm{de} \mathrm{fev.} 2016$.

BRASIL. Decreto n. 85.064 de 26 de agosto de 1980. Dispõe sobre a Faixa de Fronteira. Disponível em: http://www.planalto.gov.br/ccivil_03/decreto/Antigos/D85064.htm Acesso em: 10 fev. 2016.

BRASIL. Ministério da Integração Nacional. Secretaria de Programas Regionais. Programa de Desenvolvimento da Faixa de Fronteira. Proposta de Reestruturação do Programa de Desenvolvimento da Faixa de Fronteira. Brasília: BRASIL, 2005.

BRITO. José. Maria de. Descoberta de Foz do Iguaçu e fundação da Colônia Militar. Foz do Iguaçu: Travessa dos Editores, 2005.

BRITO, Thiago Alves Macedo de. Região: Leituras possíveis de Milton Santos (Dissertação de Mestrado). Departamento de Geografia da Universidade Federal de Minas Gerais, 2007.

CONTE, Cláudia Heloiza. Foz do Iguaçu - PR na rede de cidades. (Dissertação). Programa de Pós-Graduação em Geografia. Universidade Estadual de Maringá, Maringá. 2012. (Mestrado em Geografia).

COSTA, Gabriela Dorneles Ferreira da. MENGER, Katiele Rezer. TANCREDI, Letícia. A Reformulação dos Eixos da IIRSA. Documento do Modelo de Simulação das Nações Unidas para o Ensino Superior. UFRGSMUN, UFRGS Model United Nations. ISSN: 2318-3195. Vol. 3. P.135-168. UFRGS: 2015. 
CURY, Mauro José Ferreira. FRAGA, Nilton Cesar. Conurbação transfronteiriça e o turismo na tríplice fronteira: Foz do Iguaçu, Ciudad del Este e Puerto Iguazú. Revista Rosa dos Ventos. Vol.5, n. ${ }^{\circ} 3$, p. 460-47, jul/set. 2013.

DEBALD, Blasius Silvano. A formação continuada dos docentes nas IES privadas da fronteira trinacional. Anais. Anpuh - XXIII simpósio nacional de história - londrina, 2005. Disponível em: http://anais.anpuh.org/wp-content/uploads/mp/pdf/ANPUH.S23.1128.pdf Acesso em: 12 jun. 2017.

HAGE, José Alexandre Atahyde. Mario Travassos e a Geolopolítica Brasileira: tensões com a Argentina e preocupações com Imperialismos. Revista de Geopolítica, v.4, no. 1, p. 98-114, jan/jun. 2013.

IBGE, Instituto Brasileiro de Geografia e Estatísticas. Posição e Extensão. Disponível em: http://teen.ibge.gov.br/mao-na-roda/posicao-e-extensao.html Acesso em: 09 fev. $2016 \mathrm{a}$.

IBGE, Instituto Brasileiro de Geografia e Estatísticas. Cidades. Disponível em: http://www.cidades.ibge.gov.br Acesso em: 13 jan. 2016b.

INDEC, Instituto Nacional De Estatística Y Censos. Anuário Estagiário de La República Argentina 2014.

IPARDES. Instituto Paranaense de Desenvolvimento Econômico e Social. Oeste paranaense: $o$ $3^{\circ}$. Espaço relevante. Curitiba: IPARDES, 2008.

ITAIPU BINACIONAL. Notícias. Disponível em: https://www.itaipu.gov.br/sala-deimprensa/noticia/itaipu-recebe-860998-visitantes-e-supera-marca-de-2014 Acesso em: 13 jan. 2016.

IIRSA, Iniciativa para a integração da Infraestrutura Regional Sul-americana. Carteira de Projetos 2009. Disponível em: http://www19.iadb.org/intal/intalcdi/PE/2009/04494pt.pdf Acesso em: 05 abr. 2016.

LIMA, Perci. Foz do Iguaçu e sua história. Foz do Iguaçu: Serzegraf, 2001.

MDIC, Ministério Do Desenvolvimento, Indústria E Comércio. Estatísticas de Comércio Exterior. http:// http://www.mdic.gov.br//sitio/interna/index.php?area=5 Acesso em 11 nov. 2015.

OLIVEIRA, Francisco de. A questão regional: a hegemonia inacabada. Revista Estudos Avançados. Vol. 07. No. 18. São Paulo. Maio/Agosto, 1993.

OLIVEIRA, Monica Resende de. Mídia Impressa na Tríplice Fronteira: estudo do jornal local 'A gazeta do Iguaçu'. (Dissertação). Universidade Metodista de São Paulo. Curso de PósGraduação em Comunicação Social. São Bernardo do Campo, 2005. (Mestrado em Comunicação).

OSORIO, Jaime. América Latina: O novo padrão exportador de especialização produtiva Estudo de cinco economias da região. In: Carla Ferreira, Jaime Osorio, Mathias Luce (orgs.). Padrão de reprodução do capital: contribuições da teoria marxista da dependência. São Paulo: Boitempo, 2012.

RODRIGUES, Bernardo Salgado. O heartland sul-americano - a importância geopolítica da Bolívia para a América do Sul. Revista Oikos, Vol. 13, p. 39-55. n. 1. Rio de Janeiro, 2014.

SANTOS, Milton. Metamorfoses do Espaço Habitado, fundamentos Teórico e Metodológico da geografia. Hucitec. São Paulo, 1988.

SANTOS, Milton. A Natureza do Espaço: Técnica e tempo. Razão e Emoção. Editora da Universidade de São Paulo. São Paulo, 2006. 
SELA, Sistema Económico Latinoamericano y del Caribe. La Integración Fronteriza en el Marco del Processo de Convergencia de America Latina y El Caribe. Secretaria Permanente del SELA. Caracas Venezuela. Octubre de 2012. Disponível em: http://www19.iadb.org/intal/intalcdi/PE/2013/11724a02.pdf Acesso em 13 jun. 2017.

SEVERO, Luciano Wexell. A importância geopolítica da Bolívia e a integração da América do Sul. In: América Andina: Integração Regional, segurança e outros olhares. Organizadores: Renata Peixoto de Oliveira, Silvia Garcia Nogueira, Filipe Reis Melo. Campina Grande: eduepb, 2012.

SILVA, Micael Alvino da. Breve história de Foz do Iguaçu. Foz do Iguaçu: Epígrafe, 2014.

SOUZA, Marlei Fátima de. CORREA, João Jorge. Formação Continuada de Professores: Breves considerações sobre a formação continuada na fronteira trinacional. Anais. $1^{\circ}$. Simpósio Nacional de Educação. Unioeste Cascavel, Nov. 2008. 